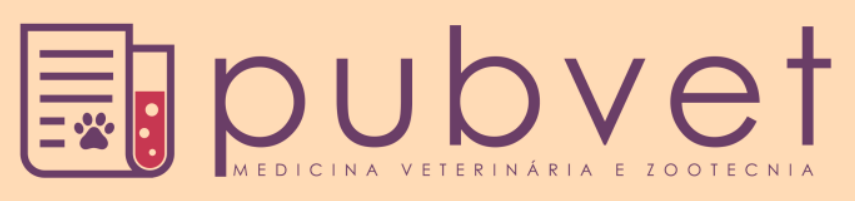

https://doi.org/10.22256/pubvet.v12n1a12.1-3

\title{
Infestação em Felis catus por Felicola subrostratus: Relato de caso
}

\author{
Natália Braz de Almeida Pereira ${ }^{\ominus 1 *}$, Lundoi Tobias Lee ${ }^{\bullet}$, Luiza da Rocha Vieira ${ }^{3}$ \\ ${ }^{1}$ Médica veterinária autônoma, Volta Redonda-RJ, Brasil. ${ }^{2}$ Bióloga, Mestre em Tecnologia ambiental, Doutoranda em Microbiologia Agrícola \\ na Universidade Federal de Lavras, Departamento de Biologia. Lavras-MG, Brasil. E-mail: lundoilee@ posgrad.ufla.br. ${ }^{3}$ Médica veterinária \\ autônoma, Volta Redonda-RJ, Brasil. \\ *Autor para correspondência, E-mail: nat.nba@hotmail.com
}

\begin{abstract}
RESUMO. A pediculose em gatos é incomum e pouco relatada. Existe uma altíssima especificidade de hospedeiro que facilita a identificação. Não sendo encontrado nenhum outro relato deste parasito no sul do estado do Rio de Janeiro (Quatis), que descreva a incidência de Felicola subrostratus nesta região do Brasil. Os sinais clínicos observados foram: Alopecias, tricorrexia, prurido intenso, irritabilidade, mudanças comportamentais, etc. Foi feita a identificação do parasito e o tratamento foi proposto, o qual foi bem-sucedido com a eliminação dos parasitos, e melhora dos sinais clínicos.
\end{abstract}

Palavras chave: ectoparasitas, felinos, pediculose

\section{Infestation in Felis catus by Felicola subrostratus: Case report}

ABSTRACT. Pediculosis in cats is uncommon and poorly reported. There is a very high host specificity that facilitates identification. No other report of this parasite was found in the southern state of Rio de Janeiro (Quatis city), which describes the incidence of Felicola subrostratus in this region of Brazil. The clinical signs observed were: Alopecia, tricorrexia, intense pruritus, irritability, behavioral changes, etc. Identification of the parasite was made and the treatment was proposed, which was successful with elimination of the parasites, and improvement of the clinical signs.

Keywords: ectoparasites, felines, pediculosis

\section{Infestación en Felis catus por Felicola subrostratus: Reporte de caso}

RESUMEN. La pediculosis en gatos es inusual y poco relatada. Hay una especificidad de huésped muy alta que facilita la identificación. No ha sido relatado casos de este parásito en el sur del estado de Río de Janeiro (municipio de Quatis), que describa la incidencia de Felicola subrostratus en esta región de Brasil. Los signos clínicos observados fueron: Alopecia, tricorrexia, prurito intenso, irritabilidad, cambios de comportamiento, etc. El parásito fue identificado y el tratamiento fue propuesto, lo que fue exitoso con la eliminación de los parásitos y la mejora de los signos clínicos.

Palabras clave: ectoparásitos, felinos, pediculosis

\section{Introdução}

O piolho é um Artrópode da classe Insecta, ordem Phthiraptera. O corpo é composto em cabeça, tórax e abdome, três pares de patas fixas ao abdome, ápteros, com metamorfose incompleta, passando pelas fases: ovo (lêndea), ninfas de $1^{\circ}, 2^{\circ}$ e $3^{\circ}$ estádios e adultos machos e fêmeas (Barbosa \& Pinto, 2003).
Os piolhos sugadores ou mastigadores podem ser reconhecidos através de inspeção, e existe uma altíssima especificidade de hospedeiro que facilita a identificação, especialmente para os hospedeiros que possuem somente um tipo de piolho (p. ex., Haematopinus suis em Sus scrofa e Felicola subrostratus em felis catus) (Urquhart, 1996, Bowman, 2010). 
Ocorre com mais frequência altas infestações por piolhos em animais negligenciados e subnutridos, podendo também, ocultar uma enfermidade subjacente. O Felicola subrostratus, faz parte da família Trichodectidae, possui aparelho bucal mastigador e são cosmopolitas, tem sido referido como um ectoparasito específico de felinos. Todavia, sua infestação é atípica (Urquhart, 1996), podendo estar presente no corpo todo, porém observa-se maior número de exemplares na face, pina e região dorsal ( $\underline{\mathrm{Scott}}$ et al., 1996).

Em animais de pêlos longos é possível abrigar populações localizadas em regiões mais profundas da pelagem, pois estes não conseguem se limpar tão bem como os de pêlos curtos (Urquhart, 1996). A irritação e o prurido estão relacionados a maior parte dos problemas resultantes da infestação, sendo que a causa destes ainda é desconhecida, porém acredita-se que não tenha somente a ver com a irritação mecânica (Zachary et al., 2012).

\section{Relato do caso}

Foi atendido em Quatis - RJ, um felino, macho, castrado, da raça PCB (pêlo curto brasileiro), 2 anos de idade, deu entrada na clínica com luxação coxo femoral após ter sofrido um atropelamento. Ao ser examinado, foi observada a presença de piolhos, alopecia, tricorrexia, prurido intenso e muitas lêndeas por todo o corpo do animal (Figura 1).

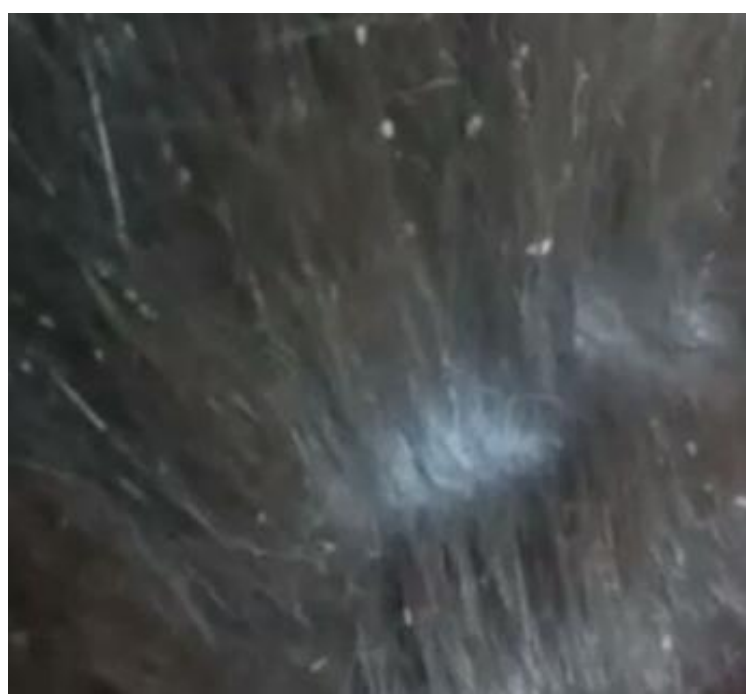

Figura 1: Presença dos ovos (lêndeas) no pelo do animal

No exame direto de pêlos sob microscopia (aumento de 100x), observou-se piolhos da espécie Felicola subrostratus (Figura 2) e a presença de ovos (lêndeas) fixos nos pêlos (Figura 3). Foram coletados manualmente com o pêlo, armazenados em álcool $70^{\circ} \mathrm{GL}$. Os exemplares foram observados ao exame microscópico após a clarificação em solução de potássio $10 \%$ em 30 minutos. O tratamento proposto foi à base de Imidacloprida, moxidectina (Advocate ${ }^{\circledR}$ ) tópico em dose única e 15 dias após, o animal passou por uma revisão, na qual retirou os pontos da cirurgia feita para corrigir a luxação causada pelo acidente e foi observada a eliminação completa dos ectoparasitas (Figura 4).

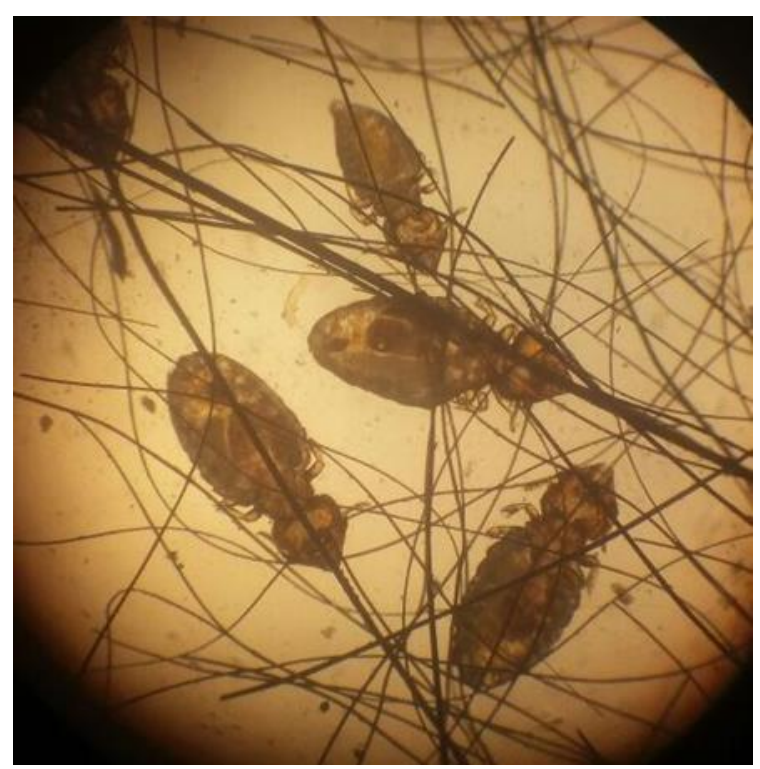

Figura 2: Felicola subrostratus direto no pêlo microscopia (aumento de 100x).

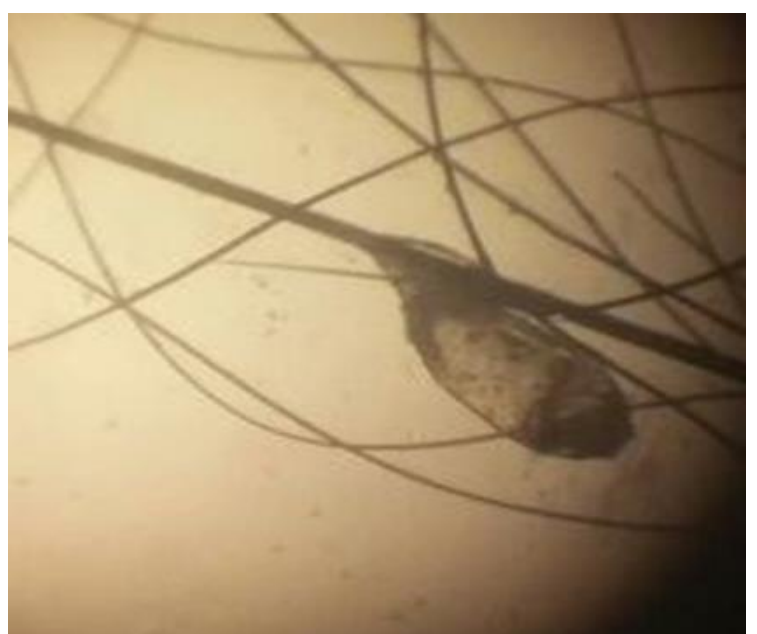

Figura 3: Ovos (lêndeas) de Felicola subrostratus direto no pêlo microscopia (aumento de 100x).

\section{Resultados e Discussão}

Pereira et al. (2005) relatam que co-infeccção autoimune possivelmente pode contribuir a associação de outras doenças, como a demoticose, esporotricose e a pediculose e complicar o quadro do paciente e dificultar a realização do diagnóstico 
definitivo. Também Aguiar et al. (2009) Observaram infestações mistas de F. subrostratus como Lynxacarus radovskyi. Segundo Scott et al. (1996), o prurido pode variar, algumas vezes pode ser intenso causando dermatites profundas, que se parece com as alergias também originadas por outros ectoparasitas.

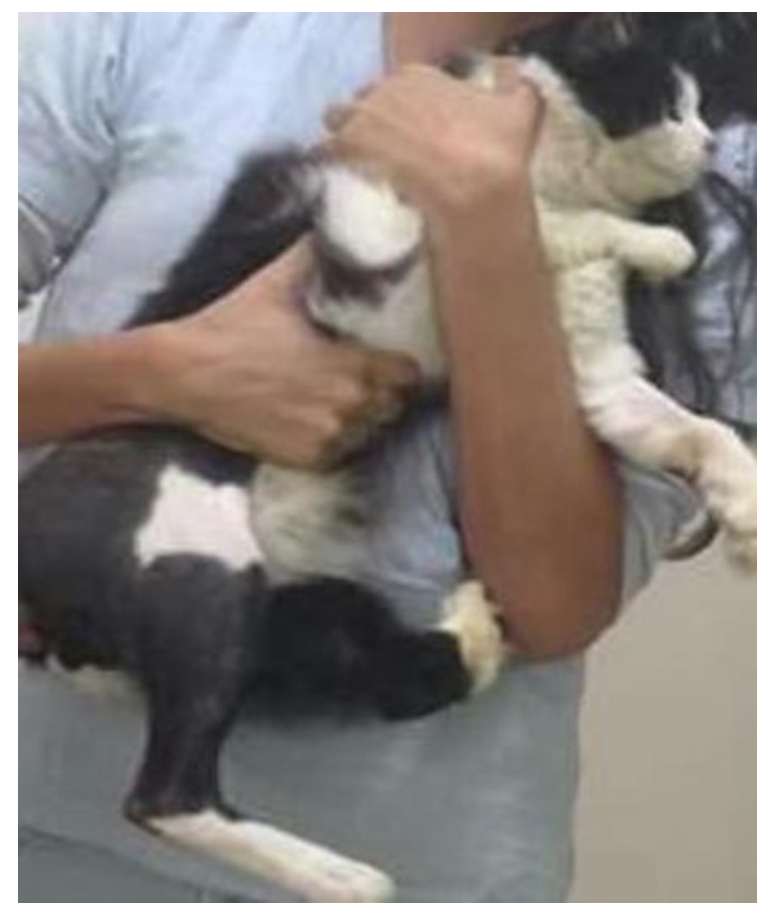

Figura 4: Individuo após tratamento.

O animal apresentava algumas áreas alopécicas e tricorrexia nos pêlos, e após meses isento de parasitismo, não houve áreas alopécicas e os pêlos estavam resistentes, confirmando assim o que foi achado por Figueiredo et al. (2013) e corroborado com o que é descrito na literatura, segundo Zachary et al. (2012) que descrevem as lesões macroscópicas como pápulas, crostas, escoriações e danos ao pêlo e a pele.

Na pediculose, os animais se arranham e ficam irritadiços, porém se houver uma infestação maciça pode deprimi-los gravemente (Urquhart, 1996).

Uma importante característica dos parasitas de felinos é que representam um risco como zoonoses, podendo oferecer risco de contágio às pessoas que lidam com esses animais (Chandler et al., 2006).

\section{Conclusão}

A pediculose é atípica em gatos. Todavia, notase a importância para o conhecimento do clínico de pequenos animais em relação as suas manifestações clínicas que podem cursar com outras patologias ou até mesmo serem confundidas com outras dermatopatias dificultando o diagnóstico e consequentemente o tratamento. Não sendo encontrado nenhum outro relato deste parasito no sul do estado do Rio de Janeiro (Quatis), o presente estudo visa colaborar com estudos epidemiológicos desse parasito no Brasil e com o tratamento para esta ectoparasitose.

\section{Referências bibliográficas}

Aguiar, J., Silva, M. M. L., Rodrigues, F. R., Stieven, H. P., Cunha, M. A. \& Zazycky, R. R. 2009. Infestação mista por Lynxacarus radovskyi e Felicola subrostratus em um gato na região de Porto Alegre, RS, Brasil. Acta Scientiae Veterinariae, 37, 301-305.

Barbosa, J. V. \& Pinto, Z. T. 2003. Pediculose no Brasil. Entomol Vect, 10, 579-86.

Bowman, D. D. 2010. Parasitologia veterinária. Elsevier.

Chandler, E. A., Gaskell, C. J. \& Gaskell, R. M. 2006. Clínica e terapêutica em felinos. Editora Roca, São Paulo.

Figueiredo, M. A. P., Manrique, W. G. \& Guerra, R. M. 2013. Felicola subrostratus parasitando gatos domésticos de São Luís, Maranhão, Brasil: relato de caso. Biotemas, 26, 255-259.

Pereira, S. A., Pacheco, S. T. M., Borges, F. F., Paes Leme, L. R., Barbieri, S. I., Okamoto, T., Cuzzi, T., Santos, R. R. \& Schubach, A. 2005. Demodicose associada à Esporotricose e Pediculose em gato co-infectado por FIV/FeLV. Acta Scientiae Veterinariae, 33, 75-78.

Scott, D. W., Muller, G. H. \& Kirk, R. W. 1996. Dermatologia dos pequenos animais. Interlivros, Rio de Janeiro.

Urquhart, G. M. 1996. Parasitologia veterinária, 2 edn. Guanabara Koogan, Rio de Janeiro.

Zachary, J. F., McGavin, D. \& McGavin, M. D. 2012. Bases da patologia em veterinária. Elsevier Brasil, Rio de Janeiro.

\section{Article History:}

Received 5 September 2017

Accepted 10 October 2017

Available on line 23 November 2017

License information: This is an open-access article distributed under the terms of the Creative Commons Attribution License 4.0, which permits unrestricted use, distribution, and reproduction in any medium; provided the original work is properly cited. 